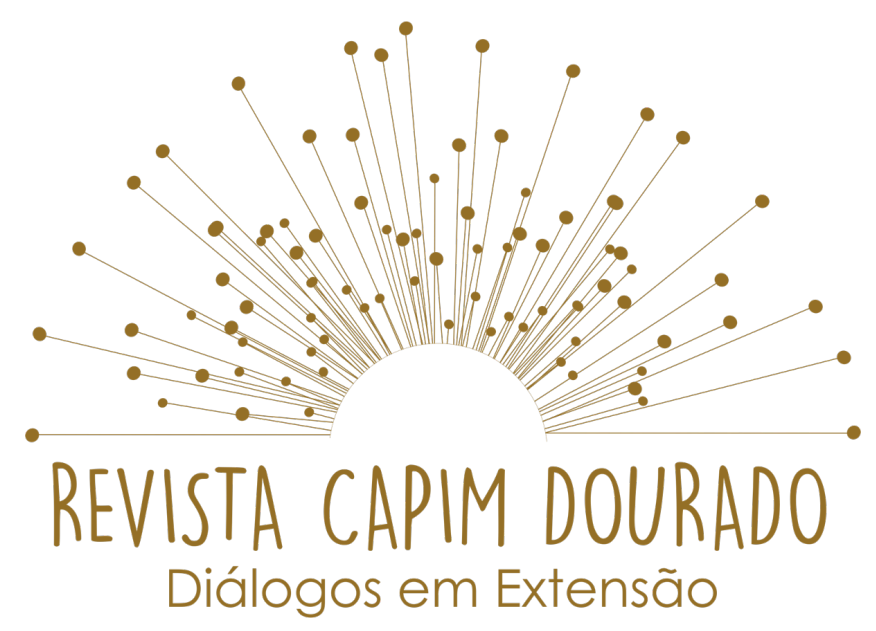

ISSN n² 2595-7341

Vol. 3, n. 1, Janeiro-Abril, 2020

DOI: http://dx.doi.org/10.20873/uft.2595-7341.2020v3n1p85

\title{
UFT EM DESTAQUE
}

FEATURED UFT

UFT DESTACADO

\section{Nathan Alves ${ }^{1}$ \\ André Demarchi ${ }^{2}$}

\section{RESUMO}

Visando a veiculação de informações referentes ao campus de Porto Nacional, da Universidade Federal do Tocantins (UFT) em seu sentido mais lato, por meio de uma plataforma audiovisual, assim obtendo a melhor comunicação e integração da comunidade acadêmica como um todo, bem como pensando em proporcionar o acesso a informações e a vivência universitária para o público externo foi criado o projeto de extensão universitária: UFT em Destaque. O presente projeto seguiu o padrão cinematográfico de produção baseado em uma divisão do trabalho que se ramifica em diversas funções de acordo com a préprodução, gravação e pós-produção, garantindo assim que a periodicidade dos programas, que foram gravados semanalmente e veiculados ao público por meio das redes sociais. A produção destes programas foi feita por alunos de todos os cursos do campus de porto nacional, todos os programas foram traduzidos para a linguagem brasileira de sinais, propiciando também a inclusão social da população usuária dessa linguagem. O projeto conseguiu alcançar seu público

\footnotetext{
${ }^{1}$ Acadêmico do curso de bacharelado em Ciências Sociais pela Universidade Federal do Tocantins (UFT), Campus de Porto Nacional, Tocantins, nathanscano@outlook.com.

2 Professor do colegiado de Ciências Sociais pela Universidade Federal do Tocantins, Campus de Porto nacional, Tocantins, andredemarchi@uft.edu.br.
} 


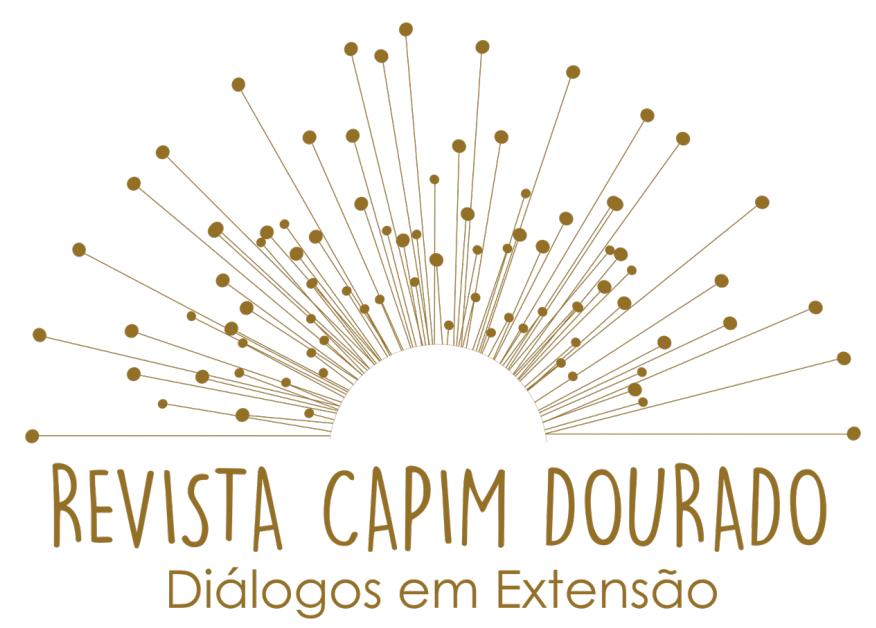

ISSN n² 2595-7341

Vol. 3, n. 1, Janeiro-Abril, 2020

DOI: http://dx.doi.org/10.20873/uft.2595-7341.2020v3n1p85

alvo (cerca de 1831 visualizações foram alcançadas), proporcionando o acesso às informações acadêmicas e à vivência universitária para o público externo, não apenas discentes, docentes e técnicos pertencentes a UFT, mas também para a comunidade em geral, permitindo que qualquer pessoa com acesso à internet possa visualizar os conteúdos e conhecer a realidade do campus, além de estender as informações sobre a vida universitária do campus de Porto Nacional para a comunidade local e para demais pessoas interessadas.

PALAVRAS-CHAVE: Comunicação. Cultura. Extensão Universitária. Jornalismo Amador. Divulgação.

\section{ABSTRACT}

Aiming to convey information regarding the Porto Nacional campus, of the Federal University of Tocantins (UFT) in its broadest sense, through an audiovisual platform, thus obtaining the best communication and integration of the academic community as a whole, as well as thinking in providing access to information and university experience for the external public, the university extension project was created: UFT em Destaque. The present project followed the cinematographic production pattern based on a division of labor that branches into several functions according to pre-production, recording and postproduction, thus ensuring that the programs' frequency, which was recorded weekly and broadcast on the public through social networks. The production of these programs was carried out by students from all courses on the campus of Porto Nacional, all programs were translated into Brazilian sign language, also enabling the social inclusion of the population using this language. The project managed to reach its target audience (about 1831 views were reached), providing access to academic information and university experience for the external public, not only students, teachers and technicians belonging to UFT, but also to the community in general, allowing anyone with access to the internet to view the 


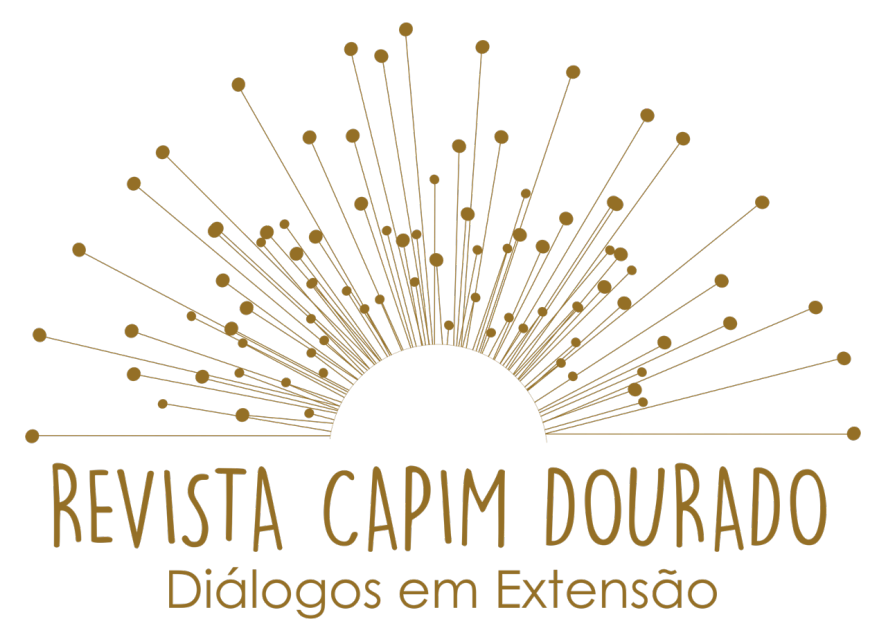

ISSN n² 2595-7341

Vol. 3, n. 1, Janeiro-Abril, 2020

DOI: http://dx.doi.org/10.20873/uft.2595-7341.2020v3n1p85

contents and get to know the reality of the campus, in addition to extending information about university life on the Porto Nacional campus to the local community and other interested people.

KEYWORDS: Communication. Culture. University Extension. Amateur Journalism. Disclosure.

\section{RESUMEN}

Palabras clave: Comunicación. Cultura. Ampliar la difusión de información sobre el campus de Porto Nacional, de la Universidad Federal de Tocantins (UFT) en su sentido más amplio, a través de una plataforma audiovisual, obteniendo así la mejor comunicación e integración de la comunidad académica en su conjunto, así como el pensamiento En la provisión de acceso a la información y experiencia universitaria para el público externo, se creó el proyecto de extensión universitaria: UFT em Destaque. El presente proyecto siguió el patrón de producción cinematográfica basado en una división del trabajo que se ramifica en varias funciones según la preproducción, grabación y postproducción, asegurando así que la frecuencia de los programas, que se grababa semanalmente y se emitía en el público a través de las redes sociales. La producción de estos programas fue realizada por estudiantes de todos los cursos en el campus de Porto Nacional, todos los programas fueron traducidos a la lengua de signos brasileña, posibilitando también la inclusión social de la población que usa esta lengua. El proyecto logró llegar a su público objetivo (se alcanzaron alrededor de 1831 visitas), brindando acceso a información académica y experiencia universitaria para el público externo, no solo estudiantes, docentes y técnicos pertenecientes a la UFT, sino también a la comunidad en general permitir a cualquier persona con acceso a Internet ver los contenidos y conocer la realidad del campus, además de ampliar la información sobre la vida 


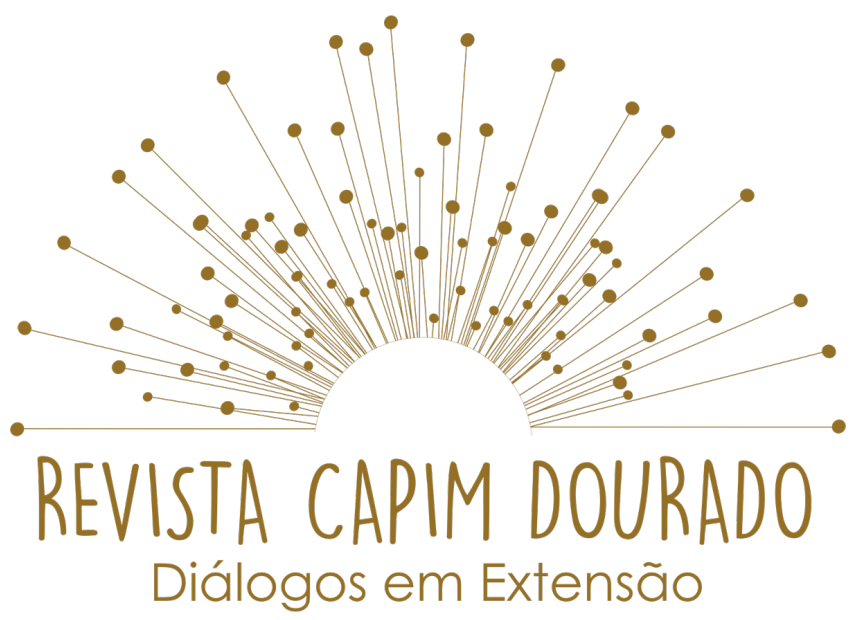

ISSN n² 2595-7341 Vol. 3, n. 1, Janeiro-Abril, 2020

DOI: http://dx.doi.org/10.20873/uft.2595-7341.2020v3n1p85

universitaria del campus de Porto Nacional a la comunidad local y otras personas interesadas. Periodismo aficionado. Divulgar.

PALABRAS CLAVE: Comunicación. Cultura. Extensión Universitaria. Periodismo aficionado. Divulgar.

Recebido em: 01.10.2019. Aceito em: 09.10.2019. Publicado em: 01.01.2020. 


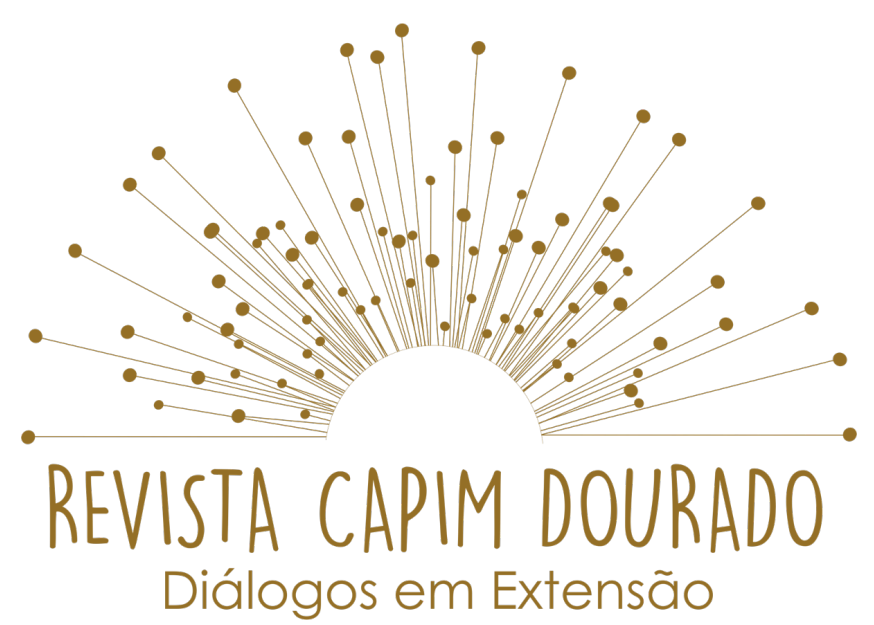

ISSN n² 2595-7341

Vol. 3, n. 1, Janeiro-Abril, 2020

DOI: http://dx.doi.org/10.20873/uft.2595-7341.2020v3n1p85

\section{INTRODUÇÃO}

O projeto visa a veiculação de informações referentes ao campus de Porto Nacional, da Universidade Federal do Tocantins (UFT) em seu sentido mais lato, por meio de uma plataforma audiovisual, assim obtendo a melhor comunicação e integração da comunidade acadêmica como um todo. Visa ainda proporcionar o acesso a informações e a vivência universitária para o público externo. A difusão de informações sobre o campus visa não apenas os Discentes e Docentes pertencentes a UFT, mas a Comunidade em geral. Qualquer pessoa com acesso à internet poderá acessar os Conteúdos e viver a realidade do campus mais abertamente, e assim melhorar a exterioridade da universidade.

Fazem parte da produção do projeto alunos de todos os cursos do campus de porto nacional, garantindo a diversidade temática e a interdisciplinaridade na escolha das pautas a serem retratadas nos programas. Além disso, todos os programas possuem tradução para a linguagem brasileira de sinais, propiciando a inclusão social da população usuária dessa linguagem.

Os programas foram gravados semanalmente e na mesma periodicidade veiculados ao público por meio das redes sociais. Para conhecer melhor o projeto assista aos vídeos já publicados na plataforma UFT EM Destaque: https://www.youtube.com/channel/UCBdeyyN7pHExpEA8kJyy3aQ

\section{METODOLOGIA}




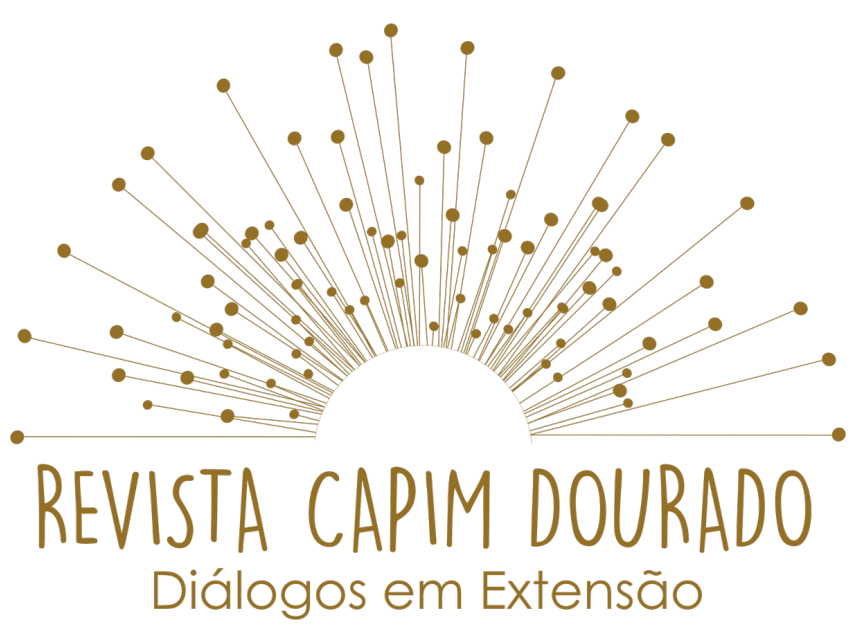

ISSN n² 2595-7341

Vol. 3, n. 1, Janeiro-Abril, 2020

DOI: http://dx.doi.org/10.20873/uft.2595-7341.2020v3n1p85

Visando a veiculação de informações referentes ao campus de Porto Nacional, da Universidade Federal do Tocantins (UFT), para se obter uma melhor comunicação e integração da comunidade acadêmica como um todo, bem como das comunidades locais, adotamos como ferramenta a plataforma audiovisual do Youtube. Principalmente por conta da amplitude que a rede social possibilita, além é claro da facilidade que a tecnologia digital e as câmeras DSRL trouxeram para que se pudesse produzir conteúdo.

A ideia foi de dar visibilidade regional e nacional para notícias, informações acadêmicas, projetos, editais, bolsas e oportunidades que impactam a vida discente, docente e das comunidades locais. Buscou-se com isso não só apresentar aspectos da vida acadêmica à própria comunidade, mas também inserir, por meio dos programas semanais, o Campus e suas especificidades em uma rede ampla de divulgação, com o intuito de fomentar a diversidade cultural, atraindo novos estudantes de todo o território Nacional para o Campus.

A produção do programa seguiu o seguinte padrão: 1) pré-produção: roteiro, tratamento do roteiro; storyboard, pesquisa; 2) produção: cenógrafa, direção, filmagem, locação, maquinista; 3) pós-produção: montagem, edição de som, edição de fotografia, design gráfico, divulgação e postagem; Os alunos se dividiram entre as funções, estudaram as áreas nas quais exerceram a atividade durante o projeto e ao final gravaram em salas de aula, espaços abertos e no estúdio de libras que foi disponibilizado pelo mesmo curso. 


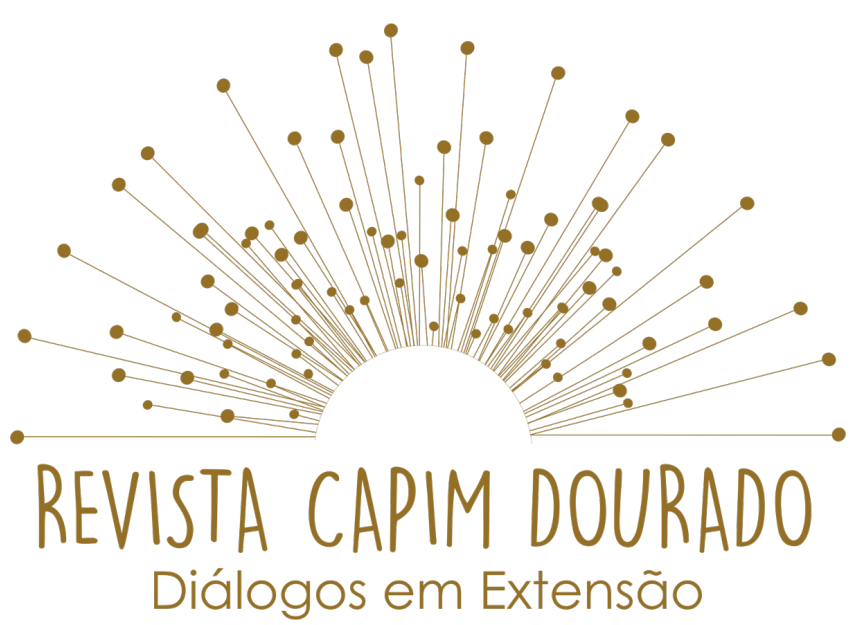

ISSN n² 2595-7341

Vol. 3, n. 1, Janeiro-Abril, 2020

DOI: http://dx.doi.org/10.20873/uft.2595-7341.2020v3n1p85

\section{FUNDAMENTAÇÃO TEÓRICA}

Assim como trazido por Lucena (2012), a facilidade na operação de câmeras digitais e o baixo custo desses equipamentos expandiram as possibilidades produções, dando assim espaço para ativistas sociais, pessoas envolvidas com pontos de cultura, oficinas nas periferias e comunidades carentes produzirem suas próprias obras audiovisuais.

Apesar de o projeto se propor a ser uma ferramenta jornalística por assim dizer, o mesmo não foi fundamentado pensando na produção editorial tradicional, por conta da amplitude do público alvo visado. Posto que se pretende uma democratização do acesso as informações referentes a universidade e a vida universitária, a fundamentação teórica foi mais voltada para a produção audiovisual.

O livro de Gerbase (2012) acerca da produção cinematográfica foi o cerne que orientou a série de procedimentos tomados pelos discentes para que a produção dos programas, principalmente no que tange a gravação, ao passo que Puccini (2012) e Murch (1992) propiciaram em suas obras um aprofundamento acerca da pré-produção e pós-produção dando subsidio teórico para o entendimento da prática do roteiro e da edição respectivamente.

Outro autor fundamental para a construção do projeto foi Duarte (2002), que contribuiu para que fosse possível a compreensão acerca da relação entre cinema e educação, propiciando também que os discentes percebessem a importância da didática para que os vídeos pudessem ser acessíveis, e assim 


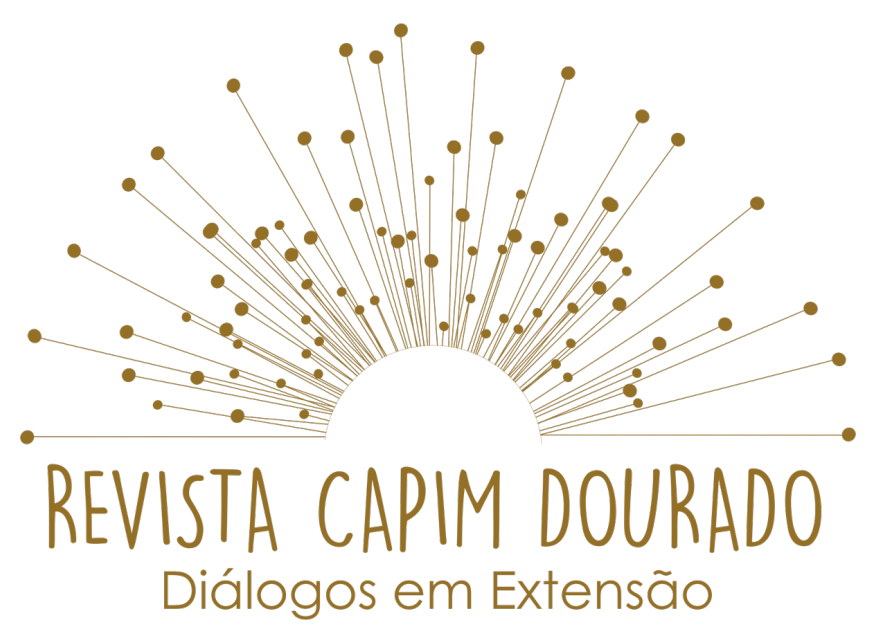

ISSN n² 2595-7341

Vol. 3, n. 1, Janeiro-Abril, 2020

DOI: http://dx.doi.org/10.20873/uft.2595-7341.2020v3n1p85

obtivesse os resultados esperados, dentre eles, e o principal: a democratização do acesso a informação dentro do campus, e para a comunidade externa.

\section{RESULTADOS FINAIS}

Os alunos envolvidos no projeto produziram assim diversos programas audiovisuais com duração máxima de cinco minutos que foram divulgados nas redes e mídias sociais com notícias referentes a vida acadêmica, política e comunitária que gira em torno do Campus e da cidade de Porto Nacional.

O projeto conseguiu assim alcançar seu público alvo, proporcionar o acesso às informações acadêmicas e à vivência universitária para o público externo, não apenas discentes, docentes e técnicos pertencentes a UFT, mas também para a comunidade em geral, permitindo que qualquer pessoa com acesso à internet possa visualizar os conteúdos e conhecer a realidade do campus. Estendeu as informações sobre a vida universitária do campus de Porto Nacional para a comunidade local e para demais pessoas interessadas. Promoveu a diversidade cultural e étnica, bem como os direitos humanos inserindo essas temáticas no conteúdo dos programas. E por fim fortaleceu os vínculos entre ensino, pesquisa e extensão garantindo na programação a divulgação de ações desses três pilares indissociáveis da universidade.

\section{CONSIDERAÇÕES FINAIS}

Os alunos desenvolveram inúmeros conhecimentos acerca da produção audiovisual, além é claro de contribuir deverás para a disseminação da 


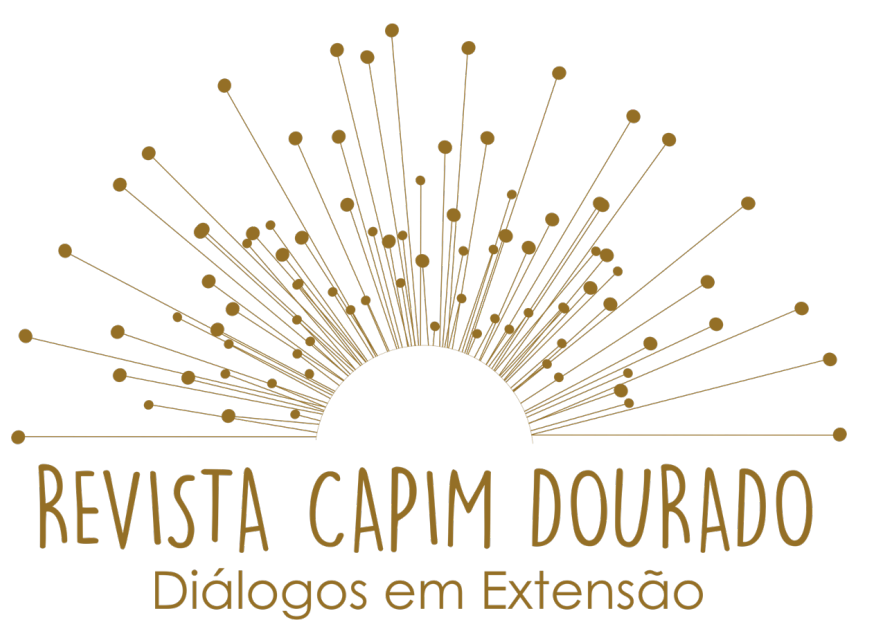

ISSN n² 2595-7341

Vol. 3, n. 1, Janeiro-Abril, 2020

DOI: http://dx.doi.org/10.20873/uft.2595-7341.2020v3n1p85

informação acadêmica como um todo, os números de visualizações foram altíssimos provando assim que o projeto foi um sucesso.

Esse projeto provou-se uma forma de democratização das informações universitárias passo em que determinados vídeos chegaram a alcançar mais de 500 visualizações. Permitimos assim com a UFT em destaque, que os alunos do campus de Porto nacional pudessem ter uma vivência plena da vida acadêmica, que estes fossem informados acerca dos eventos do campus, das oportunidades, abertura e fechamento de bolsas e principalmente de suas possibilidades enquanto parte da universidade federal do Tocantins.

\section{REFERÊNCIAS}

DUARTE, R. Cinema \& educação. Belo Horizonte: Autêntica, 2002.c

DESPLANQUES, J. DARRIÈRE L'ECRAN, Initiation au Cinéma. Paris: AGIR editora, 2012

LUCENA, L. Como fazer documentários. São Paulo: Summus editorial, 2012.

PUCCINI, S. Roteiro de documentário. Campinas: Papirus, 2012.

KEMP, P. Tudo sobre cinema. Rio de janeiro: Sextante, 2011.

ADORNO, T. W.; HORKHEIMER, M. 1985 [1947]. Dialética do esclarecimento. Rio de Janeiro: Zahar. Gerbase, Carlos.

Cinema: Primeiro Filme: Descobrindo, Fazendo, Pensando. Porto Alegre: Arte e Oficio, 2012.

SANTO, M. M. A Direção de Arte no Cinema: uma abordagem sistêmica sobre seu processo de criação. Revista Digital do LAV 10 (1), p. 14-30. 


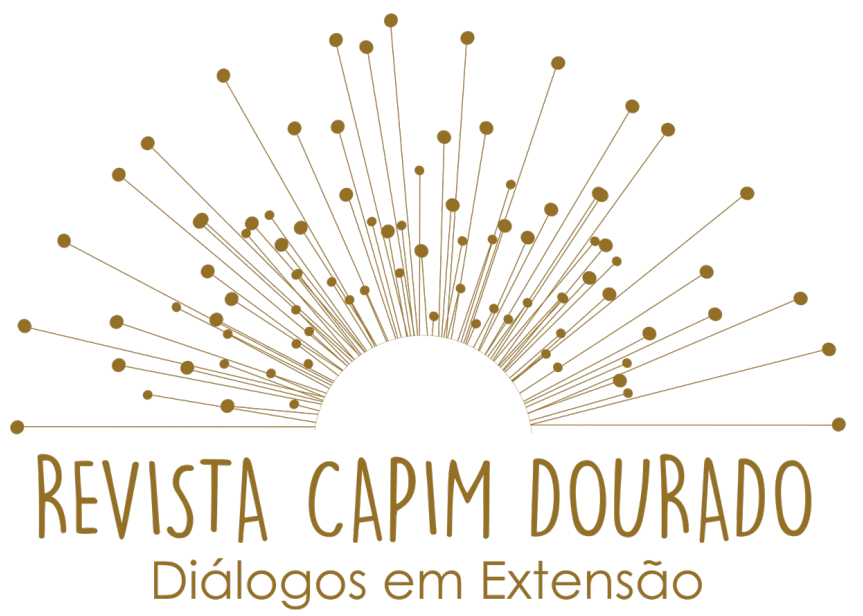

ISSN n² 2595-7341

Vol. 3, n. 1, Janeiro-Abril, 2020

DOI: http://dx.doi.org/10.20873/uft.2595-7341.2020v3n1p85

Murch, Walter. Num piscar de Olhos: A edição de um filme sob a optica de um mestre. Rio de Janeiro: Jorge Zahar Editore, 1992 